\title{
ANÁLISE MICROESTRUTURAL DA ZTA SIMULADA NA GLEEBLE DO AÇO DUPLEX SAF 2205*
}

\section{Resumo}

Lilia Olaya-Luengas ${ }^{1}$ Juan Alberto Pozo Morejón ${ }^{2}$ Mônica Costa Rezende ${ }^{3}$ Ivani de Souza Bott ${ }^{4}$

A resistência à corrosão e mecânica dos aços inoxidáveis duplex dependem da distribuição de fases, portanto, é fundamental a compreensão das transformações microestruturais que ocorrem na zona termicamente afetada (ZTA) em função do aporte de calor em processos de soldagem. A fim de investigar a evolução microestrutural no aço inoxidável duplex SAF 2205 durante a soldagem, foram simulados na Gleeble dois ciclos térmicos com aporte de calor de 15 e $30 \mathrm{~kJ} / \mathrm{cm}$, considerando a temperatura de pico de $1350^{\circ} \mathrm{C}$, seguido de têmpera a 500 e $250^{\circ} \mathrm{C}$. As microestruturas na condição de como recebido e da ZTA simulada foram caracterizadas através de microscopia óptica $(\mathrm{MO})$ e de microscopia eletrônica de varredura $(\mathrm{MEV})$. Foram utilizadas diferentes técnicas metalográficas para a caracterização da microestrutura e identificadas três diferentes morfologias de austenita: nos contornos de grão, austenita Widmanstätten e a austenita intragranular, assim como diferentes frações volumétricas destas fases.

Palavras-chave: Aços inoxidáveis duplex; Simulação física; Zona Termicamente Afetada (ZTA); Metalografia quantitativa.

\section{MICROSTRUCTURAL ANALYSIS OF A GLEEBLE SIMULATION OF THE HAZ IN SAF 2205 DUPLEX STAINLESS STEEL}

\section{Abstract}

The corrosion resistance and mechanical properties of duplex stainless steels are dependent on the phases volume fraction. Therefore, it is fundamental to understand the microstructural changes occurring in the heat affected zone (HAZ) as a function of the cooling rates associated with the heat input. In order to investigate the microstructural evolution of the HAZ in duplex stainless steel SAF 2205, a Gleeble simulation of two thermal cycles corresponding to 15 and $30 \mathrm{~kJ} / \mathrm{cm}$ with peak temperature of $1350^{\circ} \mathrm{C}$, followed by quenching at 500 and $250^{\circ} \mathrm{C}$ were performed. Microstructural characterization of the HAZ in the as-received condition and the simulated HAZ were carried out by optical microscopy (OM) and scanning electron microscopy (SEM). Different metallographic techniques were used to characterize these microstructures namely grain boundary, Widmanstätten and intragranular austenite. Additionally, the volume fraction was measured.

Keywords: Duplex stainless steel; Physical simulation; Heat Affected Zone (HAZ); Quantitative metallography.

1 Engenheira Metalúrgica, MSc, Estudante de Doutorado de Engenharia de Materiais e de Processos Químicos e Metalúrgicos, Departamento de Engenharia Química e de Materiais, PUCRio, Rio de Janeiro, RJ, Brasil.

2 Engenheiro Mecânico, PhD, Professor Titular, Facultad de Ingeniería Mecánica e Industrial, Universidad Central "Marta Abreu" de Las Villas, Santa Clara, Cuba.

3 Engenheira Metalúrgica, PhD, Especialista em Serviços Tecnológicos, Centro de Tecnologia Solda, SENAI, Rio de Janeiro, RJ, Brasil.

4 Físico, Professor Titular, Departamento de Engenharia Química e de Materiais, PUC-Rio, Rio de Janeiro, RJ, Brasil. 


\section{INTRODUÇÃO}

Os aços inoxidáveis duplex (AIDs) fornecem combinações de propriedades que não são facilmente alcançáveis em aços inoxidáveis convencionais austeníticos ou ferríticos, oferecem alta tenacidade, boa soldabilidade, proteção satisfatória à corrosão, excelente resistência à fragilização por corrosão sob tensão e alta resistência mecânica ${ }^{1}$.

Nos últimos anos, os AIDs vêm desempenhando um papel muito importante em diferentes setores da indústria tais como, petróleo, gás, indústria de processos e de produtos químicos ${ }^{2}$ assim como em aplicações importantes como os ambientes marinhos agressivos ${ }^{3}$. Atualmente há uma ampla gama de graus de AIDs e todos oferecem uma combinação atraente de elevada resistência mecânica e boa resistência à corrosão em função da microestrutura bifásica que consiste aproximadamente de $50 \%$ de ferrita e $50 \%$ de austenita ${ }^{2}$. A ferrita oferece alta resistência mecânica e resistência à fragilização por corrosão sob tensão e a austenita contribui com a boa ductilidade e com a resistência à corrosão geral ${ }^{4}$.

A aplicação prática de qualquer aço em maior escala é dependente do uso dos processos de soldagem na fabricação. A produtividade é uma questão fundamental na fabricação, e com o aumento do uso dos AIDs este aspecto se torna importante ${ }^{2}$. A soldagem é requerida na maior parte das aplicações e consequentemente a compreensão do efeito da soldagem na integridade do componente final é essencial'.

As novas metodologias de soldagem, a produção de novos aços e a ampliação das faixas de aporte de calor tem trazido mudanças na tecnologia de soldagem. Existem muitos exemplos que incluem a soldagem de AIDs como processo de fabricação, portanto as especificações de parâmetros de soldagem precisam ser criticamente reexaminadas para que sejam amplamente aceitas e aplicadas aos graus de aços mais recentes ${ }^{2}$.

A microestrutura da ZTA é determinada pelo ciclo térmico aplicado, o qual é muito sensível às variações dos parâmetros de soldagem. Nos AIDs, a ZTA geralmente se desenvolve a partir de uma estrutura que consiste de uma distribuição de fases $50: 50$, austenita em uma matriz ferrítica ${ }^{1}$. A tenacidade e a resistência à corrosão da ZTA é consequentemente dependente do balanço das duas fases ${ }^{4}$.

Os processos de soldagem podem ter efeitos significativos sobre as propriedades mecânicas e a resistência à corrosão. Por exemplo, o alto conteúdo de ferrita na ZTA prejudica essas propriedades. Além disso, é amplamente aceito que a presença de pequenas quantidades de fases secundárias pode ter efeitos nocivos importantes ${ }^{2}$. A ZTA apresenta-se ferrítica com o crescimento do grão, seguido pela nucleação e engrossamento da austenita nos contornos de grão ferríticos enquanto se resfria, ou pode apresentar uma microestrutura parcialmente transformada contendo austenita parcialmente dissolvida na ferrita ${ }^{1}$.

As altas velocidades de resfriamento envolvidas na ZTA resultam numa matriz ferrítica supersaturada com respeito tanto aos elementos de liga substitucionais quanto aos intersticiais. Isto pode levar à precipitação de fases ricas em cromo e molibdênio durante o resfriamento a partir da temperatura de pico'1.

O sistema Gleeble reproduz os ciclos térmicos que ocorrem durante a soldagem sendo, portanto uma ferramenta poderosa na previsão das propriedades da ZTA. O sistema permite selecionar um modelo matemático para o processo de transferência de calor em uma solda por arco em chapas finas, que considera um estado quase estacionário com o fluxo de calor bi-dimensional. 
Mediante a simulação da ZTA na Gleeble com dois aportes de calor diferentes foi estudado sistematicamente o comportamento microestrutural que apresenta 0 aço SAF 2205 ante aos processos de soldagem, estes processos envolvem transformações de fases a alta temperatura e a diferentes velocidades de resfriamento. Esse estudo permite estabelecer o melhor valor de aporte de calor nas soldas que garantam o equilíbrio de fases e evitem a formação de fases secundárias ou proporcionem a menor quantidade delas. Os resultados permitirão estabelecer as condições tempo-temperatura ótimas para cada um dos aços inoxidáveis duplex contemplados nesta pesquisa.

\section{MATERIAIS E MÉTODOS}

\subsection{Aço Duplex SAF 2205}

Foi utilizado o aço duplex SAF 2205 (AID de baixa liga $25 \mathrm{Cr}$ duplex) em forma de tubo sem costura, de 8 polegadas de diâmetro externo, fabricado de acordo com a norma ASTM A7896.

A composição química do aço foi testada por análise química instrumental via emissão ótica.

\subsection{Simulação do Diagrama de Fase no software Thermo-Calc}

O diagrama de fases do aço inoxidável duplex em estudo foi obtido utilizando o software Thermo-Calc $4.1 \mathrm{com}$ a base de dados TCFE3.

\subsection{Simulação Física da ZTA na Gleeble}

Os corpos de prova do aço duplex SAF 2205 foram usinados conforme as dimensões mostradas na Figura 1(a). Foi selecionado o modelo Rykalin 2D para simular os ciclos térmicos que ocorrem durante um processo de soldagem real. As simulações foram executadas mantendo a câmara da Gleeble com pressão de $5 \times 10^{-3}$ torr e com dois aportes de calor diferentes, 15 e $30 \mathrm{~kJ} / \mathrm{cm}$, conforme Figura $1(\mathrm{~b})$.

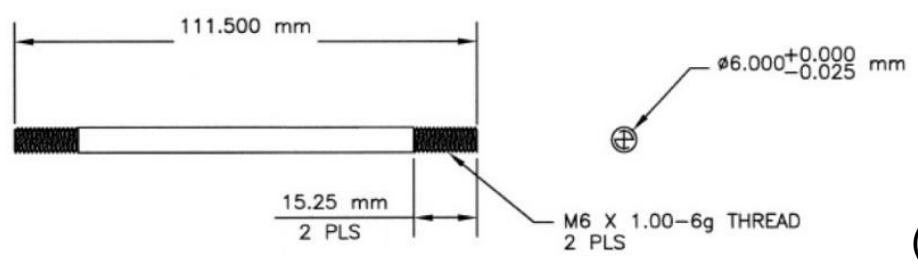

(a)

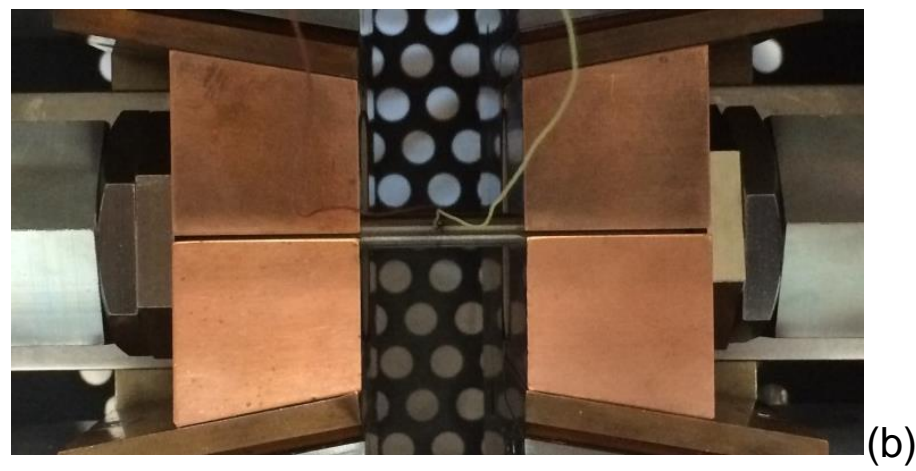

Figura 1. Desenho do corpo de prova do aço SAF 2205 (a) e câmara da Gleeble (b). 
Os ciclos térmicos foram programados utilizando taxa de aquecimento de $350^{\circ} \mathrm{C} / \mathrm{s}$ desde a temperatura ambiente até a temperatura de pico que corresponde à temperatura de ferritização completa do aço segundo os resultados obtidos pelo Thermo-Calc, com tempo de permanência de 2 segundos.

Depois do aquecimento foram programadas as taxas de resfriamento para dois grupos de corpo de prova, segundo o modelo Rykalin 2D. Para um primeiro grupo esse resfriamento foi até $500^{\circ} \mathrm{C}$ (nesta temperatura considera-se que o processo de formação de austenita foi concluído ${ }^{7,8}$ ); seguido de uma têmpera até a temperatura ambiente. O segundo grupo foi resfriado até $250^{\circ} \mathrm{C}$ (nessa temperatura considerase que os processos de transformações de fases foram finalizados), e seguido de uma têmpera até a temperatura ambiente.

Os dados das propriedades físicas do aço SAF 2205 inseridos na Gleeble para gerar os ciclos térmicos foram:

Condutividade térmica $(\lambda)=0,22 \mathrm{~J} /\left(\mathrm{s} \mathrm{cm}^{\circ} \mathrm{C}\right)$

Calor específico $(c)=0,68 \mathrm{~J} /\left(\mathrm{g}^{\circ} \mathrm{C}\right)$

Densidade $(\rho)=7,8 \mathrm{~g} / \mathrm{cm}^{3}$

Os aportes de calor e os tempos de resfriamento $\boldsymbol{t}_{12 / 8}$ (desde $1200^{\circ} \mathrm{C}$ até $800^{\circ} \mathrm{C}$ ) e $\boldsymbol{t}_{8 / 5}$ (desde 800 até $500^{\circ} \mathrm{C}$ ) correspondentes aos ciclos térmicos aplicados nos corpos de prova durante a simulação física na Gleeble são apresentados na Tabela 1.

Tabela 1. Tempos de resfriamento nos aportes de calor de 15 e $30 \mathrm{~kJ} / \mathrm{cm}$.

\begin{tabular}{|l|c|c|}
\hline \multirow{2}{*}{} & \multicolumn{2}{|c|}{ Aportes de Calor [kJ/cm] } \\
\cline { 2 - 3 } & $\mathbf{1 5}$ & $\mathbf{3 0}$ \\
\hline $\boldsymbol{t}_{12 / 8}[\mathbf{s}]$ & 14,4 & 57,7 \\
\hline $\boldsymbol{t}_{8 / 5}[\mathbf{s}]$ & 42,5 & 169,8 \\
\hline
\end{tabular}

\subsection{Caracterização Metalográfica}

As amostras da seção longitudinal do tubo na condição de como recebido e as amostras simuladas foram preparadas para análises metalográficas, da forma convencional. Foram utilizados dois métodos de ataque: ataque químico com solução Behara modificada $\left(10 \mathrm{ml}\right.$ de $\mathrm{HCl}, 0,35 \mathrm{gr}$ de $\mathrm{K}_{2} \mathrm{~S}_{2} \mathrm{O}_{5}$ em $70 \mathrm{ml}$ de água destilada) durante $8 \mathrm{~s}$ e ataque eletrolítico com solução de $\mathrm{KOH}$ ao $50 \%$ e $3 \mathrm{~V}$ durante $10 \mathrm{~s}$.

As micrografias do aço duplex SAF 2205 na condição de como recebido e com ZTA simulada foram analisadas. O software Fiji foi utilizado para o processamento digital das imagens e as contagens de fases.

\section{RESULTADOS E DISCUSSÃO}

\subsection{Análise Química}

O aço duplex em estudo apresenta um teor de nitrogênio um pouco elevado, quase o dobro do valor estabelecido pela norma ASTM A240', a qual estabelece a faixa de nitrogênio entre 0,14 e $0,20 \%$ em peso. O aumento no teor de nitrogênio pode promover a formação de fases secundárias ricas neste elemento durante os tratamentos térmicos. 
Tabela 2. Composição química do aço duplex SAF 2205.

\begin{tabular}{|c|c|c|c|c|c|c|c|c|c|c|}
\hline & $\mathbf{C}$ & $\mathbf{S i}$ & $\mathbf{M n}$ & $\mathbf{P}$ & $\mathbf{S}$ & $\mathbf{C r}$ & $\mathbf{N i}$ & $\mathbf{M o}$ & $\mathbf{N}$ & $\mathbf{S i}$ \\
\hline $\begin{array}{c}\mathbf{A S T M} \\
\mathbf{A 2 4 0 - 1 5} \\
\text { Tipo 2205 }\end{array}$ & $\leq 0,030$ & $\leq 2,00$ & $\leq 0,030$ & $\leq 0,020$ & $22,0-23,0$ & $4,5-6,5$ & $3,0-3,5$ & $\begin{array}{c}0,14- \\
0,20\end{array}$ & $\leq 1,00$ \\
\hline $\begin{array}{c}\text { Sandvik } \\
\mathbf{S A F} \\
\mathbf{2 2 0 5}{ }^{10}\end{array}$ & $\leq 0,030$ & $\leq 1,0$ & $\leq 2,0$ & $\leq 0,030$ & $\leq 0,015$ & 22 & 5 & 3,2 & 0,18 & - \\
\hline $\begin{array}{c}\text { Análise } \\
\text { Química }\end{array}$ & 0,025 & 0,498 & 0,82 & 0,027 & 0,0041 & 22,48 & 5,21 & 3,25 & 0,40 & $\begin{array}{c}\text { Não } \\
\text { determi } \\
\text { nado }\end{array}$ \\
\hline
\end{tabular}

\subsection{Diagrama de Fases}

Os diagramas de fases do aço SAF 2205 de Calliari ${ }^{11}$ e o obtido pelo Thermo-Calc mostram que durante o aquecimento a temperatura na qual começa a aparecer o estado líquido é $1356^{\circ} \mathrm{C}$. A partir de $1319^{\circ} \mathrm{C}$ a austenita desaparece completamente durante $\mathrm{o}$ aquecimento permanecendo somente ferrita entre essas temperaturas. Por esse motivo a temperatura de pico programada para obter a completa ferritização do aço foi de $1350^{\circ} \mathrm{C}$.

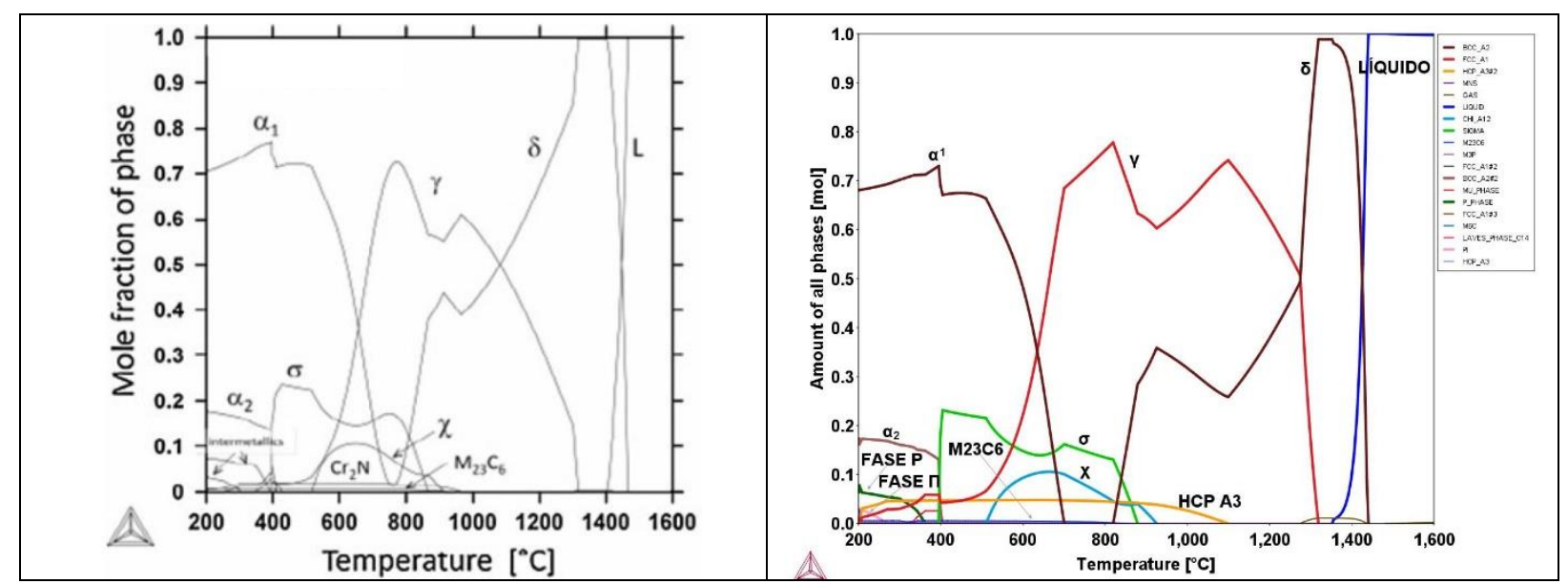

Figura 2. Diagrama de fases do aço duplex SAF $2205^{9}$ e o obtido pelo Thermo-Calc.

\subsection{Simulador Termo-Mecânico Gleeble}

A Tabela 3 mostra os ciclos térmicos aplicados com os dois aportes de calor programados de 15 e $30 \mathrm{~kJ} / \mathrm{cm}$ segundo o modelo Rykalin 2D conforme a Tabela 4.

Tabela 3. Ciclos térmicos simulados segundo o modelo Rykalin 2D no aço SAF 2205.

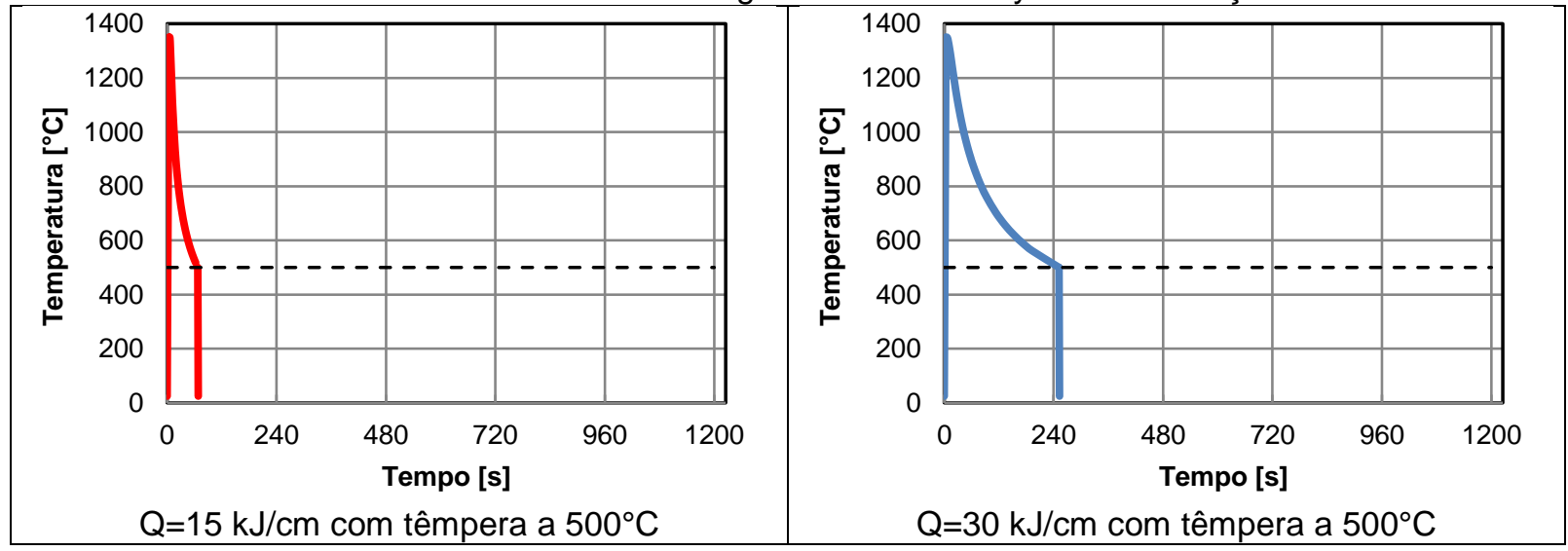




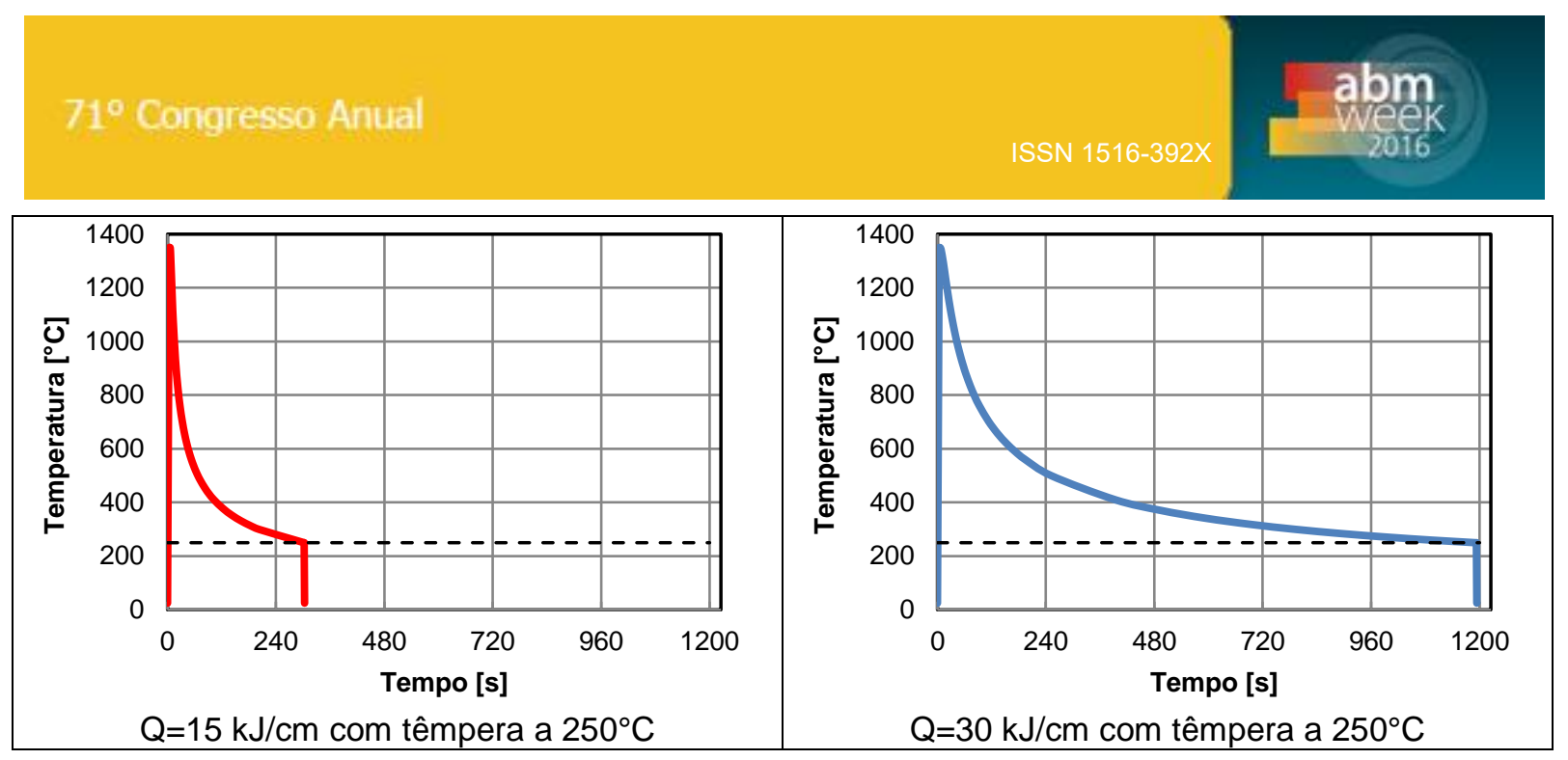

Tabela 4. Corpos de prova analisados.

\begin{tabular}{|l|l|l|}
\hline Corpos de Prova & Resfriamento & Quantidade \\
\hline Sem tratamento (como recebido) & - & 1 Corpo de Prova \\
\hline ZTA com $15 \mathrm{~kJ} / \mathrm{cm}$ de aporte de calor & $\begin{array}{l}\text { Resfriado até } 500^{\circ} \mathrm{C} \text { segundo o } \\
\text { modelo Rykalin 2D e temperado }\end{array}$ & 1 Corpo de Prova \\
\hline ZTA com 15kJ/cm de aporte de calor & $\begin{array}{l}\text { Resfriado até } 250^{\circ} \mathrm{C} \text { segundo o } \\
\text { modelo Rykalin 2D e temperado }\end{array}$ & 1 Corpo de Prova \\
\hline ZTA com 30kJ/cm de aporte de calor & $\begin{array}{l}\text { Resfriado até } 500^{\circ} \mathrm{C} \text { segundo o } \\
\text { modelo Rykalin 2D e temperado }\end{array}$ & 1 Corpo de Prova \\
\hline ZTA com 30kJ/cm de aporte de calor & $\begin{array}{l}\text { Resfriado até } 250^{\circ} \mathrm{C} \text { segundo o } \\
\text { modelo Rykalin 2D e temperado }\end{array}$ & 1 Corpo de Prova \\
\hline
\end{tabular}

\subsection{Caracterização Metalográfica}

A análise metalográfica mostra a presença de grãos claros, que foram identificados como grãos de austenita, bem como regiões escuras correspondentes à matriz ferrítica do aço. Observou-se que os grãos de austenita primária apresentavam um formato alongado devido ao processo de fabricação dos tubos, enquanto que os grãos da austenita intragranular tinham formato diferente e tamanho menor, conforme mostrado na Figura 3.

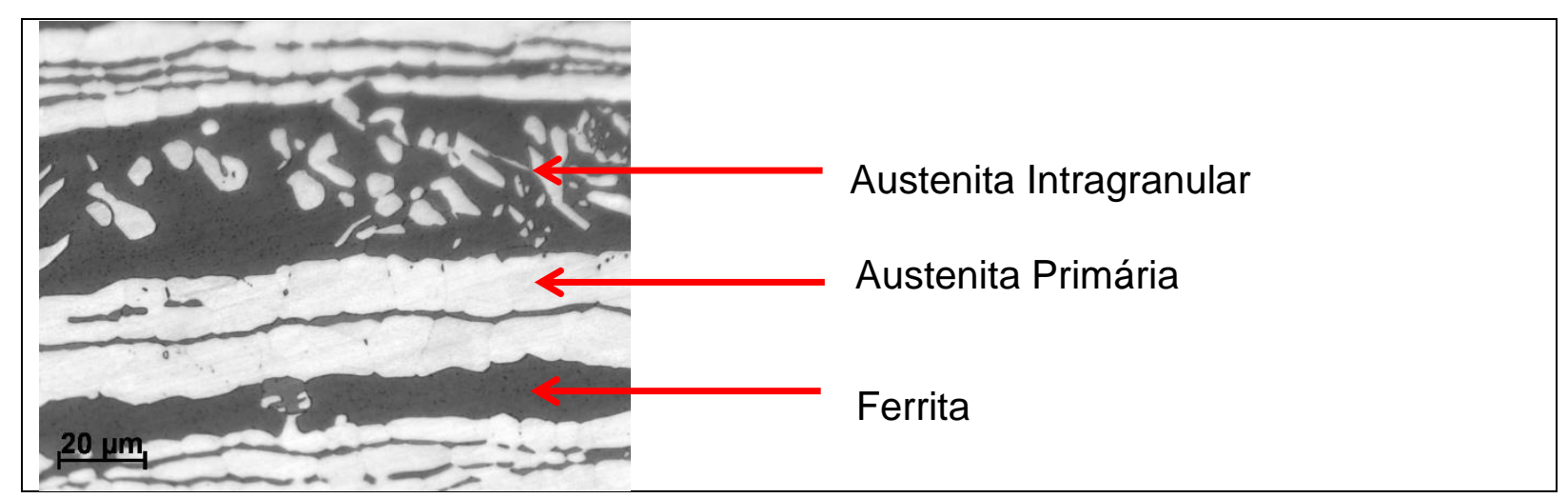

Figura 3. Micrografia com magnificação de 1000X do aço duplex SAF 2205 na condição de como recebido e com ataque químico.

Os dois tipos de ataques (Figura 4) revelaram os contornos de grãos e atacaram a fase ferrítica preferencialmente como o esperado. A ferrita apresenta uma cor cinza escura. Observou-se uma reação leve entre o eletrólito do ataque eletrolítico $(\mathrm{KOH})$ com a austenita, o que não contribui favoravelmente para o contraste das fases. Por outro lado, o ataque químico com a solução Behara permitiu obter um maior 
contraste quando comparado com a austenita, o que facilitou o processamento digital de imagens e a consequente contagem de fases.
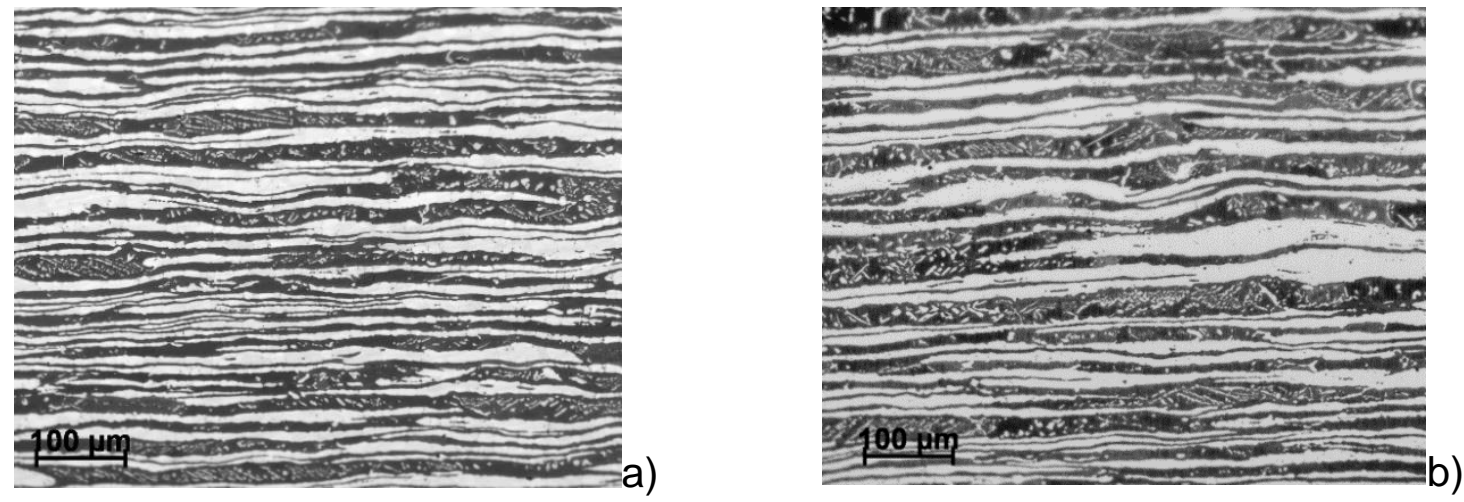

Figura 4. Micrografias a $200 X$ por microscopia ótica com os dois tipos de ataque. (a) químico com solução Behara e (b) eletrolítico com solução de $\mathrm{KOH}$.

Embora dentre as imagens referentes a ambos os tipos de ataques supracitados, o químico seja o mais recomendável para as contagens de fases por causa do maior contraste, optou-se por realizá-las com os dois tipos de ataques. Foram processadas digitalmente 20 micrografias de cada tipo de ataque para medir as frações de fases presentes.

Os resultados (Tabela 5) mostram não haver uma diferença relevante quanto à fração volumétrica medida. Portanto, qualquer um dos ataques mencionados pode ser considerado para o cálculo das frações de volume das fases. Diante disso, para os posteriores cálculos de fração volumétrica só foram realizados ataques químicos com a solução Behara modificada.

O balanço de fases Austenita/Ferrita no aço duplex SAF 2205 foi conforme o esperado. Sabendo-se que, a norma prevê que este tipo de aço deve manter a proporção de fases de 50/50.

Tabela 5. Porcentagens de fases calculadas por métodos de análises digital de imagem do aço SAF 2205 com diferentes ataques.

\begin{tabular}{|l|l|l|}
\hline Tipo de ataque & Austenita, [\%] & Matriz Ferrítica, [\%] \\
\hline Ataque químico (Solução Behara) & $47,517 \pm 0,6$ & $52,483 \pm 0,6$ \\
\hline Ataque eletrolítico (Solução de KOH 50\%) & $47,274 \pm 0,4$ & $52,726 \pm 0,4$ \\
\hline
\end{tabular}

A ZTA obtida pela simulação apresenta as duas fases iniciais, austenita e ferrita. A morfologia das fases mudou totalmente, apresentando austenita intergranular, Widmanstätten e intragranular na matriz ferrítica, além de algumas estruturas dendríticas.

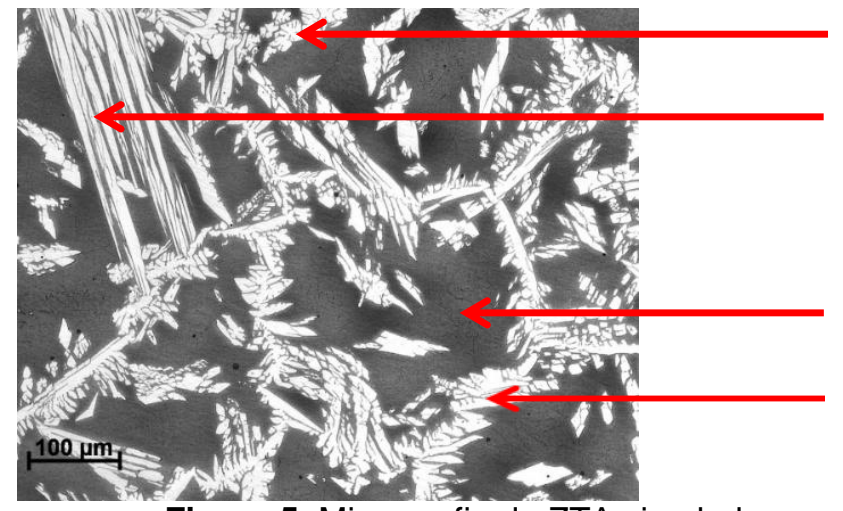

Austenita dendrítica

Austenita Widmanstätten

Ferrita

Austenita Intragranular

Figura 5. Micrografia de ZTA simulada com $30 \mathrm{~kJ} / \mathrm{cm}$ temperada a $250^{\circ} \mathrm{C}$ 
Comparando as micrografias das amostras simuladas com aportes de calor de 15 $\mathrm{kJ} / \mathrm{cm}$ (temperadas a 500 e $250^{\circ} \mathrm{C}$ ) e $30 \mathrm{~kJ} / \mathrm{cm}$ (temperadas a 500 e $250^{\circ} \mathrm{C}$ ) observou-se que à medida em que ocorre o incremento do aporte de calor 0 tamanho de grão tende a aumentar tanto da austenita quanto da ferrita (Figura 6). No caso da ferrita, nas amostras temperadas a $500^{\circ} \mathrm{C}$, o tamanho do grão aumentou mais de $25 \%$ (de $192 \mu \mathrm{m}$ para $243 \mu \mathrm{m}$ ). Enquanto que as temperadas a $250^{\circ} \mathrm{C}$, 0 aumento do tamanho de grão foi maior do que $50 \%$ (de $238 \mu \mathrm{m}$ para $400 \mu \mathrm{m}$ ), isso quando incrementou-se o aporte de calor de 15 até $30 \mathrm{~kJ} / \mathrm{cm}$.

Além disso, verificou-se que este aumento do tamanho de grão tanto da ferrita quanto da austenita quando aumenta-se o aporte de calor está relacionado com os $t_{12 / 8}$ e $t_{8 / 5}$. Neste sentido, para o aporte de calor de $30 \mathrm{~kJ} / \mathrm{cm}, t_{12 / 8}$ e $t_{8 / 5}$ são 4 vezes maiores do que o $t_{12 / 8}$ e $t_{8 / 5}$ correspondentes ao aporte de calor de $15 \mathrm{~kJ} / \mathrm{cm}$, oferecendo assim maior tempo para que os grãos de ferrita e austenita possam crescer. Logo, nota-se que, os grãos se tornam grosseiros como consequência do aumento do aporte de calor e do tempo de resfriamento.

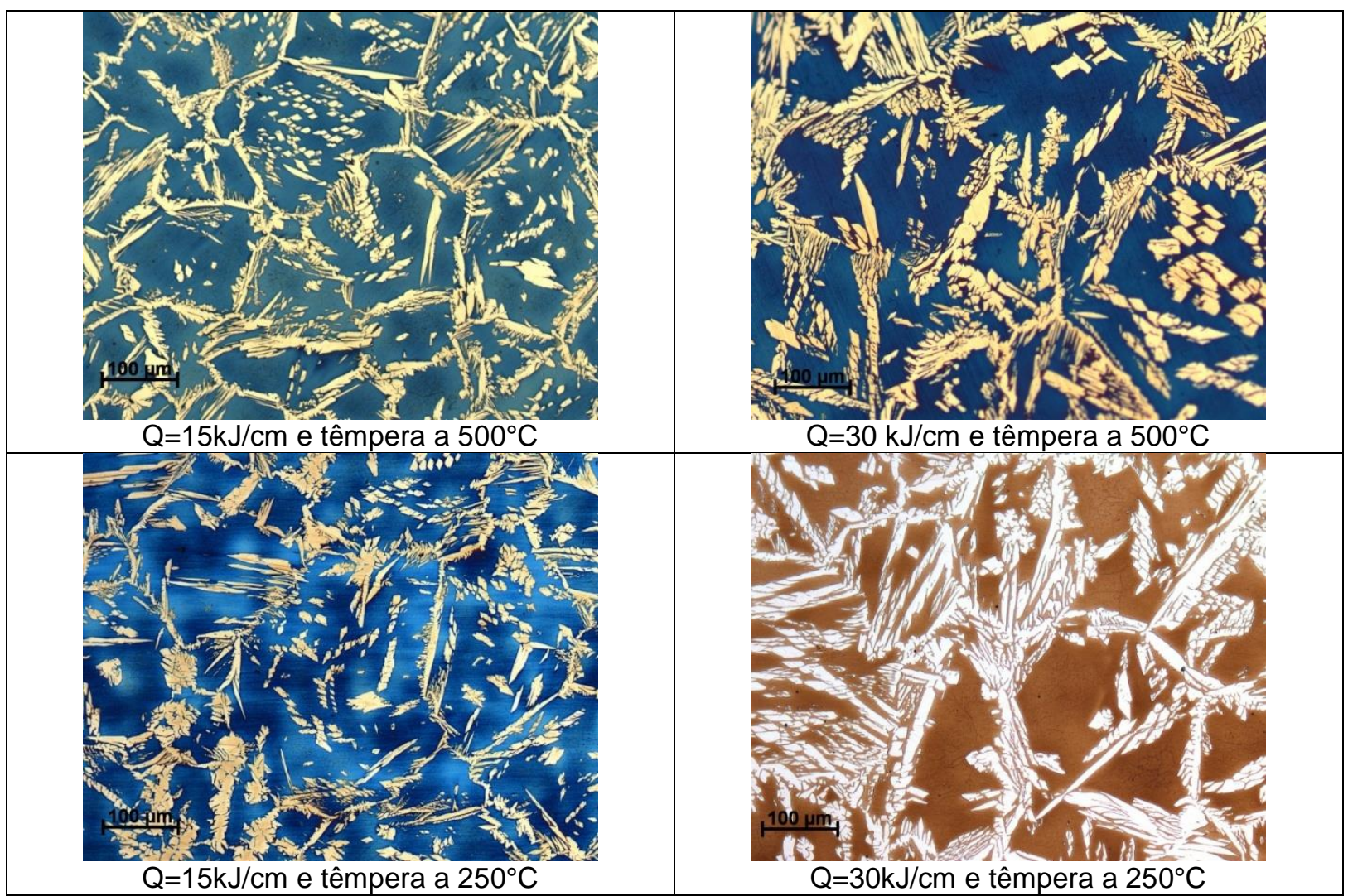

Figura 6. Micrografias das ZTA simuladas com aportes de calor de 15 e $30 \mathrm{~kJ} / \mathrm{cm}$.

Na Figura 7 mostra-se o efeito do aporte de calor na fração de fases. Os resultados obtidos nas contagens de fases da ZTA simulada são apresentados na Tabela 6 . 0 aporte de calor de $30 \mathrm{~kJ} / \mathrm{cm}$ gera maior quantidade de austenita devido ao maior tempo de resfriamento $t_{12 / 8}$ que facilita o crescimento desta fase. 
Tabela 6. Porcentagens de fases calculadas por métodos de análise digital de imagem do aço SAF 2205 com dois aportes de calor.

\begin{tabular}{|l|l|l|}
\hline Aporte de Calor & Austenita & Matriz Ferrítica \\
\hline $\begin{array}{l}\mathrm{Q}=15 \mathrm{~kJ} / \mathrm{cm} \\
\text { e têmpera } \text { a } 500^{\circ} \mathrm{C}\end{array}$ & $28,099 \pm 0,3 \%$ & $71,901 \pm 0,3 \%$ \\
\hline $\begin{array}{l}\mathrm{Q}=15 \mathrm{~kJ} / \mathrm{cm} \\
\text { e têmpera a } 250^{\circ} \mathrm{C}\end{array}$ & $26,741 \pm 0,3 \%$ & $73,259 \pm 0,3 \%$ \\
\hline $\begin{array}{l}\mathrm{Q}=30 \mathrm{~kJ} / \mathrm{cm} \\
\text { e têmpera } \mathrm{a} 500^{\circ} \mathrm{C}\end{array}$ & $34,127 \pm 0,4 \%$ & $65,873 \pm 0,4$ \\
\hline $\begin{array}{l}\mathrm{Q}=30 \mathrm{~kJ} / \mathrm{cm} \\
\text { e têmpera } \mathrm{a} 250^{\circ} \mathrm{C}\end{array}$ & $35,082 \pm 0,5 \%$ & $64,918 \pm 0,5 \%$ \\
\hline
\end{tabular}
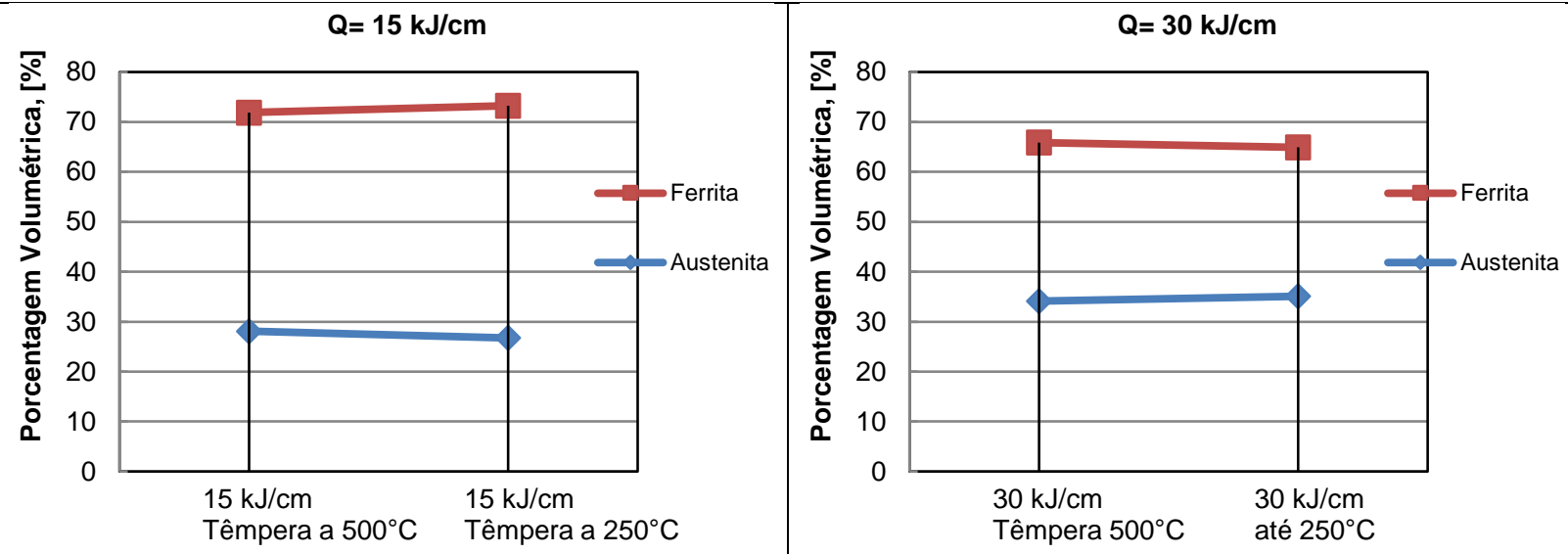

Figura 7. Comparação das Porcentagens de fases vs. Aporte de Calor.

\section{CONCLUSÃO}

O presente trabalho objetivou-se principalmente a simulação da ZTA no aço inoxidável duplex SAF 2205 na Gleeble com dois aportes de calor e o estudo da evolução microestrutural durante a soldagem, o qual permitiu formular as seguintes conclusões:

1. O tamanho de grão da ferrita e austenita na ZTA foi afetado pelo aporte de calor, ou seja, quanto maior é o aporte de calor, maior é o tamanho de grão. Isso como consequencia do incremento do $t_{12 / 8}$ e $t_{8 / 5 . q u e}$ faciliam ao crescimento dos grãos.

2. Com relação às contagens de fases, identificou-se que quanto maior for o aporte de calor maior a formação de austenita.

3. O diagrama de fase do aço SAF 2205 realizado no Thermo-Calc revelou que nas temperaturas inferiores a $500^{\circ} \mathrm{C}$ a presença de austenita é menor do que a temperaturas superiores. Isso é evidenciado ao comparar a quantidade de austenita nas amostras temperadas a $500^{\circ} \mathrm{C}$ com aquelas que continuaram no resfriamento programado até ser temperadas a $250^{\circ} \mathrm{C}$. A quantidade de austenita formada novamente até os $500^{\circ} \mathrm{C}$ é de aproximadamente $34 \%$, quase a mesma que aquela encontrada a $250^{\circ} \mathrm{C}$.

\section{Agradecimentos}

Os autores agradecem à CAPES e à FAPERJ pelo suporte financeiro, que permitiu a realização do presente trabalho. 


\section{REFERÊNCIAS}

1 Atamert, S.; King, J. E. Super duplex stainless steels. Part 1 Heat affected zone microstructures. Materials Science and Technology, 1992, v. 8, n. 10, p. 896-911.

2 Karlsson, L. Welding Duplex Stainless Steels - A Review of Current Recommendations. Welding in the World, 2012, v. 56, n. 5-6, p. 65-76.

3 Ezuber, H. M.; El-Houd, A.; El-Shawesh, F. Effects of sigma phase precipitation on seawater pitting of duplex stainless steel. Desalination, 2007.

4 Westin, E. M. et al. Laser Welding of a Lean Duplex Stainless Steel. $26^{\text {th }}$ International Congress on Applications of Lasers and Electro-Optics, ICALEO 2007: Congress Proceedings, 2007, p. 335-344.

5 Sieurin, H.; Sandström, R. Sigma phase precipitation in duplex stainless steels 2205. Materials Science and Engineering: A, 2007, v. 444, n. 1-2, p. 271-276.

6 ASTM. A789-13: Standard Specification for Seamless and Welded Ferritic/Austenitic Stainless Steel Tubing for General Service, 2013.

7 Yang, Y. et al. The effect of large heat input on the microstructure and corrosion behavior of simulated heat affected zone in 2205 duplex stainless steel. Corrosion Science, 2011, v. 53, p. 3756-3763.

8 Kuroda, T. et al. Role of Austenite in Weld Toughness of Super Duplex Stainless Steel. Welding in the World, v. 49, n. 5-6, p. 29-33.

9 ASTM A240-15b: Standard Specification for Chromium and Chromium-Nickel Stainless Steel Plate, Sheet, and Strip for Pressure Vessels and for General Applications, 2015.

10 Sandvik. Sandvik SAF 2205 (Tube and pipe, seamless). 2015. Disponível em: < www.smt.sandvik.com/en/materials-center/material-datasheets/tube-and-pipeseamless/sandvik-saf-2205/?pdf $=1>$.

11 Calliari, I. et al. The phase stability in $\mathrm{Cr}-\mathrm{Ni}$ and $\mathrm{Cr}-\mathrm{Mn}$ duplex stainless steels. Journal of Materials Science, v. 46, 2011, p. 6916-6924. 